\title{
NA MÁQUINA DO TEMPO DE PAPEL: COMBA MALINA E A IMPORTÂNCIA DA FICÇÃO CIENTÍFICA DE DINAH SILVEIRA DE QUEIROZ
}

\author{
Ana Rüsche (USP) \\ Pilar Lago e Lousa (Unicamp)
}

\begin{abstract}
Recebido em 04 abr 2019. Ana Rüsche é Doutora em Estudos Linguísticos e Aprovado em 02 mar 2020. Literários em Inglês na Faculdade de Filosofia, Letras e Ciências Humanas da Universidade de São Paulo - FFLCH-USP; escritora, autora de "A telepatia são os outros" (Monomito, 2019), "Do amor" (Novela, São Paulo: Quelônio, 2018) e "Furiosa" (Poesia, São Paulo: Ed. Autora, 2015); participa da Fantástika 451; pesquisa utopia, feminismo e ficção científica anglófona e brasileira. Lattes: http://lattes.cnpq. br/3640438371450743. Site: www.anarusche.com. E-mail: anarusche@gmail.com.
\end{abstract}

Pilar Lago e Lousa é Doutoranda em Teoria Literária na Unicamp; é professora de escrita criativa e literatura; escritora e autora de "Bruxisma" (Poesia, Urutau: 2019) e "Ultraviolenta"(Poesia, Kotter, 2017); é mediadora do Leia Mulheres Osasco; pesquisa literatura brasileira, latino-americana, poesia marginal-periférica e teoria literária, com especial interesse em estudos de gênero e decoloniais. Lattes: http://lattes.cnpq. br/8736718765654690.

E-mails: pilarbu@gmail.com / pilar.morfica@gmail.com. 
Resumo: Durante quatro décadas de intensa produção, Dinah Silveira de Queiroz (1911-1982) publicou quase vinte livros e teve uma carreira literária recheada de prêmios. Versátil, a autora escreveu contos, romances, crônicas e produziu conteúdo para rádio e jornal. Pioneira, integrou a primeira onda da Ficção Científica brasileira. Atuou de maneira fundamental na luta pelo ingresso das mulheres na Academia Brasileira de Letras e, em 1981, tomou posse como imortal. Sem se eximir do debate, problematizou questões importantes em sua obra, como o lugar da mulher na sociedade, as dinâmicas coloniais excludentes e fez críticas aos regimes ditatoriais. Mesmo com tamanha expressividade no meio literário, a autora ainda é pouco lida na atualidade. Entre viagens interplanetárias e diálogos telepáticos, propomos, nesse estudo, partir de seu livro Comba Malina (1969) para entender: a inserção da escritora na Ficção Científica Brasileira; os motivos de seu apagamento; as rupturas e permanências propostas por sua escrita; e a importância do resgate de sua produção.

Palavras-chave: Dinah Silveira de Queiroz; Ficção Científica Brasileira; Comba Malina; Estudos de Gênero.

Abstract: After four decades of intense production, Dinah Silveira de Queiroz (1911-1982) had published almost twenty books and had an award-winning literary career. Embracing a variety of fields, the author wrote short stories, chronicles, novels and produced newspaper and radio content as well. She is regarded as a foremost figure of the First Wave of Brazilian Science Fiction. Queiroz played a significant role in women's rights in Academia Brasileira de Letras (the Brazilian Literary Society) and, in 1981, her membership plead was accepted. In her work, the author discussed major issues, such as the role of women in society, social exclusion and totalitarianism 
in the postcolonial context. Even with such impressive literary legacy, her work remains relatively unknown today. In this study, between interplanetary voyages and telepathic dialogues, we present her book Comba Malina (short stories, 1969) to discuss: her role as a Science Fiction writer; the reasons for her deletion; ruptures and constants in her production; and the importance of honoring her memory nowadays.

Keywords: Dinah Silveira de Queiroz; Brazilian Science Fiction; Comba Malina; Gender Studies.

Que destino terá a obra de um escritor de nossa época quando raiar o século XXI? Dinah Silveira de Queiroz

A pergunta da escritora paulistana Dinah Silveira de Queiroz ecoa através das décadas como um sinal, uma dobra no tempo que procura ligar duas pontas distantes, passado e presente. É também nossa fagulha inicial para questionar por que não ouvimos falar com tanto afinco dela e de outras escritoras como vemos aplaudidos os homens ao longo da história. Ainda indagaremos por quais motivos a Ficção Científica Brasileira sofre um apagamento constante nas memórias literárias, esse bastante democrático com relação a gênero: obras nem de mulheres ou homens são muito lembradas. Considerando que Dinah é fundamental para ambas as discussões, elegemos seu livro de contos Comba Malina (1969) para servir de guia.

Uma pista que podemos usar para desvendar o apagamento da obra de Dinah Silveira de Queiroz como um todo pode residir na própria tradição do arquivamento de nossa historiografia literária. Se a história apresentada como universal postula a noção de um "nós" que é masculino, fazendo com que "a história das mulheres 
desenvolva-se à sua margem" (COLLING, 2014, p.12), na literatura não é diferente, visto que ela é "feita de exclusões e se define tanto pelo que recusa e ignora quanto pelo que aceita e consagra" (MARTINS Apud DUARTE, 2016, p.9).

O privilégio de determinados grupos, em virtude das relações de poder, dentro do cânone literário nacional, exclui e silencia, em geral, minorias sociais como as mulheres, as pessoas negras, os pobres, a população LGBTQI+. Entretanto, no caso de Dinah Silveira de Queiroz, parecem existir outros elementos que contribuem para essa obliteração, que serão abordados ao longo deste estudo.

O fato é que, quase 50 anos depois, em artigo comemorativo ao Suplemento de Pernambuco (RÜSCHE, 2019, s/p.), apresenta-se a pergunta da Dinah, epígrafe desse artigo: "Que destino terá a obra de um escritor de nossa época quando raiar o século XXI?". A pergunta, escrita na caligrafia da própria escritora com data de 1971, foi recuperada por Bella Josef, historiadora da literatura hispano-americana, ao elaborar o perfil Seletas de Dinah Silveira de Queiroz (1974). Depois a indagação foi também transcrita por Cláudia Thomé ao analisar 16 crônicas de Dinah veiculadas na Rádio MEC e Rádio Nacional no livro Literatura de ouvido (THOMÉ, 2015). Assim, a pergunta é trazida, por meio de uma máquina de tempo de papel - feita das tintas da memória de outras mulheres -, a quem se destina a carta de fato, nós, os "donos do mundo vertiginoso que vai nascer" (2015, p.17).

Como nós, cidadãos de um mundo, agora nem tão recémnascido, olharemos para a obra de uma autora que possuía uma preocupação genuína com a permanência de sua escrita, com as 
mudanças tecnológicas do porvir, mas que, ao mesmo tempo, é ainda pouco lida? Há que se entrar novamente na máquina do tempo de papel e atar presente e passado num desejo de reparação próprio do nosso tempo, a contemporaneidade. Não queremos, contudo, esgotar as análises, fechar as temáticas, impossibilitar novos caminhos de diálogos literários. Muito pelo contrário, é preciso romper silêncios e desconstruir interdições. Este artigo é também uma pergunta para as pessoas do futuro. Um chamamento para a escuta de Dinah Silveira de Queiroz, que, atravessando as décadas, nos encontra por meio de sua literatura.

\section{NA MÁQUINA DO TEMPO: EM BUSCA DE DINAH}

Pesquisadoras debruçaram-se sobre a obra de Dinah Silveira de Queiroz ao longo dos últimos anos, mas ainda são poucos os estudos elaborados em torno de sua produção tendo em vista a extensão de sua obra e a importância de sua atuação no contexto em que estava inserida. Entre os mais importantes, destacamos: o trabalho de Zahidé Muzart (2013), que traz um panorama sobre a sua obra, uma apresentação que procura mostrar ao leitor a importância da autora e sua robustez; o livro, já mencionado, sobre as crônicas de rádio de Dinah, pesquisa de Cláudia Thomé (2015); o artigo de Constância Lima Duarte (2016) que inscreve a autora nas escritoras da geração de 1930 que foram apagadas, mas urge serem lembradas; a fresquíssima pesquisa de Ana Cristina Steffen (2019), que faz um importante e detalhado estudo a respeito do livro Margarida La Rocque: ilha dos demônios.

Muitos pontos de convergência emergem desses textos e o que mais salta aos olhos é a versatilidade de Dinah Silveira de Queiroz. 
Isto porque ela transitou por diversas formas narrativas, a saber: romance, conto, crônica, artigos, dramaturgia e foi uma importante representante da Ficção Científica nacional. Com quase vinte livros publicados ao longo de quatro décadas, é realmente impressionante que seu nome seja pouco mencionado.

Especificamente sobre a Ficção Científica Brasileira, destacamse estudos de David Dunbar (1976), Elizabeth Ginway (2005), Fabiana Pereira (2005), Roberto Causo (2013) e Matangrano e Tavares (2018), os quais abordam a produção de Dinah dentro de um rol mais amplo de autorias. Existe ainda o artigo de Veronica Eloi de Almeida (2012), a respeito de A muralha e a representação indígena nas cinco produções televisivas que sucederam à publicação do romance, com ênfase na de Maria Adelaide Amaral.

Dinah Silveira de Queiroz nasceu em São Paulo, em 1911. Mulher branca, oriunda de uma família de posses, escritores e intelectuais, frequentou o tradicional colégio feminino Des Oiseaux, onde estudaram depois Marta Suplicy e Ruth Cardoso. Segundo Constância Lima Duarte, assim como muitas escritoras produtivas de sua época, autoras que escreviam nos anos 30 no Brasil, a autora estava distante do "projeto modernista tal como ele foi elaborado" (DUARTE, 2016, p.10) e envolvida com outro projeto ideológico importante, que era a luta pela "emancipação da mulher" (2016, p.10). E seus questionamentos podiam ser vistos tanto em sua literatura quanto em sua postura diante da sociedade.

Segundo Ana Cristina Steffen (2019), Dinah Silveira de Queiroz registra números expressivos e interessantíssimos. A autora lançou seu primeiro livro em 1939, Floradas na Serra, cuja recepção foi 
imediata e teve sua tiragem esgotada em vinte dias. Posteriormente, devido ao grande sucesso, em 1954, a obra seria adapta para o cinema tendo Cacilda Becker como a estrela principal (STEFFEN, 2019, p.14). A adaptação de suas obras para outras plataformas não parou por aí, visto que A Muralha, romance histórico de 1954, publicado em homenagem às festas do IV Centenário da Fundação de São Paulo, foi adaptado cinco vezes, sendo a mais conhecida uma minissérie da TV Globo, escrita por Maria Adelaide Amaral, e exibida no ano 2000.

Entre outras obras importantes, publicou em 1949 Margarida La Rocque: a ilha dos demônios, livro traduzido para diversas línguas e lançado em países como Canadá, Coreia do Sul, Espanha, França, Itália, Japão e Portugal. Bastante aclamado, é considerado um best-seller, assim como Verão dos infiéis, de 1968. Em 1960, Dinah Silveira de Queiroz publica o livro de contos Eles Herdarão a Terra em que a autora "já manifestava seu interesse pela ficção científica" (MUZART, 2013, p.163). Ainda segundo Muzart (2013, p.163), esse interesse pela Ficção Científica irá se consolidar em outro livro de contos seu, Comba Malina, de 1969, que é objeto de estudo do presente artigo.

A autora esteve presente na rádio e no jornal, abrindo diálogo com mulheres da mais variada ordem, donas-de-casa e/ ou trabalhadoras, por meio de dicas de beleza, receitas culinárias, entre outros feitos. Ainda nos jornais, atuou como cronista e "assinou as seções 'Jornalzinho Pobre' do Jornal do Comércio, do Rio de Janeiro, e 'Café da Manhã', do também carioca A Manhã, no qual abriu espaço para divulgação de textos produzidos por jovens escritores" (STEFFEN, 2019, p.16). Dinah Silveira de Queiroz 
relacionava-se com quem a lia de um jeito diferente, de forma mais direta, buscando proximidade. Ao veicular sua obra em mídias massivas, como jornais e crônicas na rádio, utilizava seu nome civil. Outras pessoas, para poupar a face social, utilizavam-se de pseudônimo, pois a exposição em colunas sobre temas domésticos seria considerada pouco recomendável para a carreira - por exemplo, Clarice Lispector assinava como Helen Palmer quando contribuía ao Correio Feminino, coluna do Correio da Manhã em 1959 (THOMÉ, 2015).

Mostrava-se versátil também na predileção por narrativas populares, que podia ser percebida em suas escolhas: o romance histórico, a ficção científica, a fantasia e a crônica. Sua trajetória literária foi marcada por muitos prêmios, tais como: Antônio de Alcântara Machado (1940) por Floradas na Serra; Afonso Arinos da Academia Brasileira de Letras (1950), por sua única peça teatral, Oitavo dia; e Machado de Assis da Academia Brasileira de Letras (1954) pelo conjunto da obra.

As suas lutas não foram travadas apenas no âmbito da escrita, a autora tinha um grande apreço pela luta das mulheres e reivindicou de maneira contundente a inserção delas na Academia Brasileira de Letras. Pleiteou uma cadeira na ABL por três vezes: nas duas primeiras, 1970 e 1979 não foi bem-sucedida, ainda que tivesse apoio de muitos intelectuais. Enfrentou as normas sexistas da instituição e, em 1981, um ano antes de sua morte, foi empossada.

Quatro anos depois de sua prima não-consanguínea, Rachel de Queiroz, ter sido aprovada como a primeira mulher a entrar na $A B L$, Dinah Silveira de Queiroz assumiu a cadeira de número 7, 
cujo patrono é Castro Alves. Para Nélida Piñon, segundo consta nos estudos de Michele Fanini (2009), a nomeação de Dinah se dá num contexto de reparação histórica, haja vista que o seu ingresso é muito mais expressivo do que o de Rachel, por tratar-se de uma mulher que travava suas conquistas amplamente no campo político e ser assumidamente feminista, enquanto a segunda estava muito mais alinhada aos interesses dos homens.

O pioneirismo de Dinah Silveira de Queiroz não se dá apenas no contexto de sua entrada na $A B L$, mas também no discurso proferido em sua posse e na postura combativa. Segundo Rita Bittencourt, a autora tinha muita consciência do que era assumir a cadeira de Castro Alves, da importância das questões levantadas pelo autor, por isso "ao evocar os versos do poeta dos escravos e ao montar uma série genealógica dos que procuram sobretudo a liberdade, cujas representantes, naquele momento, seriam ela e todas as mulheres, torna visíveis os resultados de sua luta" (BITTENCOURT, 2018, p.42) ao longo de mais de duas décadas pela inserção das mulheres na instituição.

Rita Bittencourt (2018, p.42) salienta que, em 1981, Dinah Silveira de Queiroz usou de seu privilégio para operar (com seu discurso de posse) duas importantes provocações dentro da instituição: a) citar o intelectual e poeta senegalês Léopold Sédar Senghor e chamar atenção a necessidade de escutar vozes silenciadas; b) incorporar o conceito de negritude, cunhado por ele e pelo poeta martinicano Aimé Cesaire e que mais tarde seria usado por estudos de raça e classe. Por mais que a escritora tenha sido uma pioneira em diversos aspectos dentro da $\mathrm{ABL}$, a casa de Machado de Assis segue configurada como um reduto machista e excludente em sua maioria. 
A mesma associação que imortalizou Castro Alves e Dinah Silveira de Queiroz deixou de contemplar Conceição Evaristo em 2018, quem pleiteava a mesma cadeira de número 7. A entidade ainda não possui uma mulher negra no seu seleto grupo de imortais. Muito ligada às tradições canônicas, a instituição ainda tem algumas reparações históricas para deflagrar.

Com uma obra tão intensa e cheia de nuanças, interessa-nos neste artigo percorrer alguns caminhos: a) verificar como se deu a inserção de Dinah Silveira de Queiroz no boom da Ficção Científica Brasileira; b) diante do livro Comba Malina, efetuar a análise de três contos: "Ânima”, "Os Possessos de Núbia" e "Eles Herdarão a Terra", a fim de verificar quais problematizações estéticas e temáticas a autora propõe e quais permanências podem ser verificadas; c) evidenciar os possíveis motivos do apagamento da obra da autora; d) compreender a atualidade de sua produção.

Comba Malina aparece aqui como um fio condutor que nos guia pelo universo do insólito, de outros mundos possíveis e para uma crítica contundente às dinâmicas da sociedade na busca por uma Dinah cuja produção permaneça, contrariando as expectativas de um destino pautado no esquecimento.

\section{NO BOOM DA FC NO BRASIL: A PRIMEIRA ONDA}

A periodização mais utilizada para descrever diferenças entre produções da Ficção Científica Brasileira é a proposta pelas críticas Andrea L. Bell e Yolanda Molina-Gavilán, na introdução à antologia Cosmos Latinos: An Anthology of Science Fiction From Latin America and Spain (CAUSO, 2013). Segundo esta proposta, os dois livros de contos de FC de Dinah Silveira de Queiroz acomodam-se na Primeira 
Onda da FC Brasileira, considerado por Bell e Molina-Gavilán o período entre 1958 e 1972.

Embora o pioneiro Jerônymo Monteiro tenha publicado Três meses no século 81 (1947) e A cidade perdida (1948) e haja uma tradição brasileira precursora, prefere-se considerar o primeiro boom da produção a partir do ano de 1958: momento em que Roberto Scavone lança O Homem Que Viu o Disco-Voador e a editora Cultrix lança a antologia Maravilhas da Ficção Científica, organizada por Fernando Correia da Silva e Wilma Pupo Nogueira Brito.

O primeiro livro de contos de ficção científica de Dinah irá colaborar para a periodização, Eles Herdarão a Terra é de 1960, um título relevante para a nascente FC. Traz as seguintes narrativas: "A Universidade Marciana", "O Carioca", "Eles Herdarão a Terra", "Partido Nacional" e "A Mão Direita". Lançado pela editora-símbolo do período, a GRD, cujo editor baiano é Gumercindo Rocha Dorea, reúne aspectos de mercado que irão sedimentar a produção da Primeira Onda: divulgar narrativas de uma escritora com público consolidado e voz presente em jornais, televisão e rádio. Esse modelo será aplicado para outros títulos das Edições GRD, trazendo boa visibilidade à ficção científica nacional - o paulista Jerônymo Monteiro e a cearense Rachel de Queiroz, ambos muito conhecidos do público, serão convidados para publicarem também. $\mathrm{O}$ alcance da fórmula editorial é tal que a Primeira Onda é também apelidada por "Geração GRD", alcunha dada pelo escritor e crítico pernambucano Fausto Cunha. A GRD ainda apresentará escritores jovens, como André Carneiro, e divulgará narrativas das teatrólogas Lúcia Benedetti e Zora Seljan. 
Sobre as características centrais da produção do período do início da Primeira Onda, Ramiro Giroldo aponta que, antes de tudo, se trata de um grupo de autores heterogêneo, que se utilizam de formas narrativas e poéticas distintas "para alcançar um objetivo símile" (GIROLDO, 2012, p.15). Esses objetivos comuns podem ser descritos de duas maneiras: procurar uma compreensão do que é ser brasileiro por meio da alteridade, a comparação com a literatura anglófona, e refletir a respeito do emprego de tecnologias. Elizabeth Ginway sugere que

a ficção científica, com um gênero associado ao Primeiro Mundo, torna-se uma mistura curiosa no Brasil. Ao mesmo tempo como resistência a, e aceitação processo de modernização, ela com frequência projeta mitos brasileiros de identidade herdados do passado, para uma sociedade do futuro, como uma forma de oposição cultural à tecnologia percebida como ameaça. (2005, p.16)

É importante, entretanto, situar Comba Malina, publicado em 1969, na época de amadurecimento dessa primeira geração. Não sairá pela GRD e sim pela Laudes, trazendo na capa o selo "Dinah Fantástica", mostrando a força do nome da autora - outro volume da coleção foi a reedição de Margarida La Rocque. São oito contos, com três reedições de Eles Herdarão a Terra, na seguinte ordem: "Comba Malina", "Os Possessos de Núbia", "O Céu Anterior", "A Universidade Marciana” (reedição), "Anima”, "A Ficcionista”, "Eles Herdarão a Terra" (reedição) e "O Carioca" (reedição).

Roberto Causo destaca que, ao final da Primeira Onda, surge um conjunto de publicações dentro de uma nova fase, "um ciclo de utopias e distopias políticas e ecológicas preocupadas com 
a denúncia do regime militar (1964-1985), da tecnocracia e das consequências desumanizadoras da modernização do país" (CAUSO, 2013, p.8). Nesse final de Primeira Onda da FC, a ficção científica irá explorar temas distópicos, procurando realizar uma "crítica oblíqua ao regime militar instalado em 1964, e à tecnocracia que o acompanhava" (2013, p.220).

Comba Malina, embora seja uma publicação prévia à mencionada produção com tons distópicos, ${ }^{1}$ em alguns momentos, adianta esse sentimento de impotência e perseguição diante do acirramento dos anos de chumbo. Para exemplificar, no conto que dá nome ao volume, mesclam-se dois momentos históricos por meio de uma máquina do tempo: o Rio de Janeiro imperial e o então presente. O tema da perseguição a determinado grupo de pessoas está tematizado no conto, mas deslocado cronologicamente - em lugar de se criticar os dias presentes (suposto final da década de 1960), o conto discute uma violação inscrita em nossa historiografia: a perseguição e deportação da população cigana.

Lourival Andrade Júnior contextualiza o "controle sobre os ciganos que eram enviados ao Brasil" (ANDRADE 2013, p.101), ao analisar documento de 1718 de D. João V, recuperado por Rodrigo Corrêa Teixeira: "vários ciganos - homens, mulheres e crianças devido ao seu escandaloso procedimento neste reino" (TEXEIRA Apud ANDRADE, 2013, p.101). Na ficção, essa mulher perseguida, a cigana Comba Malina, é uma prisioneira, mas "o dono da bodega deu dinheiro aos guardas e tirou a mulher do Campo dos Ciganos" (QUEIROZ, 2001, p.14) - local que efetivamente existiu, situado na

1 Citados pelo autor: "O Copo de Cristal", de Jerônymo Monteiro; "Sociedade Secreta", de Domingos Carvalho da Silva; "O Olho Mágico", de Wladyr Nader; e "Diário da Nave Perdida" ou "O Casamento Perfeito", de André Carneiro (CAUSO, 2013, p.220). 
atual Praça da República na cidade do Rio de Janeiro. A vida da cigana, comprada, terá validade curta: será perseguida pelo populacho até ser morta queimada. Mesmo que a cigana seja retratada de forma inapropriada com estereótipos, a narrativa denuncia o machismo sistemático com motivação racista e religiosa do presente brasileiro. Qual o destino, além do linchamento, para quem for ou se portar de maneira diferente da cartilha da família brasileira? Assim, Comba Malina é um livro interessante para apresentar a Primeira Onda da FC, pois parte de seus momentos mais efusivos e iniciais de 1960 até passar um fechamento de perspectiva que traz o ano de 1969.

\section{MOTIVOS DO APAGAMENTO: SER MULHER E DAS POPULARES}

São complexas as questões que envolvem o fabular a respeito do apagamento de vozes na história da literatura. Como o esquecimento de Dinah é emblemático e muito mais profundo do que sofrem outras escritoras brancas do período (STEFFEN, 2019, p.18-19) - para uma comparação simples, os nomes de Lygia Fagundes Telles e Nélida Piñon ressoam muito mais hoje - faz-se necessário aventar algumas hipóteses para o fato. O caso de Dinah parece extraordinário, principalmente se considerar o volume de vendas, com muitos bestsellers, traduções a outros idiomas e a quantidade de adaptações ao cinema e televisão. Mesmo hoje é raro escritora com sucesso semelhante. Anota-se que o segundo marido da escritora, diplomata cearense Dário Moreira de Castro Alves, foi responsável por insistir em preservar a memória de sua obra.

Trabalha-se com duas hipóteses sobrepostas para o apagamento: ser mulher e ter se dedicado às literaturas populares, como a FC. Ramiro Giroldo faz um alerta, ao tratar sobre a 
questão do apagamento de escritores de ficção científica: "a razão para o esquecimento há de variar para cada autor, e precisa ser investigada caso a caso" (2012, p.15), o que se levará em conta na análise, principalmente por Dinah ter sido algo que hoje se traduz por "midiática".

Os estudos de Zahidé Muzart (2000, p.18) apontam que o apagamento das mulheres na literatura brasileira se dá desde o esquecimento das escritoras do século XIX. A estudiosa nos chama atenção para o fato de que a sistemática exclusão de mulheres do cânone literário está vinculada ao fato de que a crítica e a historiografia foram durante muito tempo práticas masculinas. Isto porque o campo literário, assim como a sociedade, é um espaço de disputa do discurso em que está em jogo, entre outras questões, a autoridade científica e o capital simbólico. Se a história das mulheres, como postula Perrot (2003), foi, durante séculos, uma história de silêncios, a presença delas na literatura também se configura por certas interdições.

É preciso salientar que "a produção de livros de mulheres, ainda que hoje desaparecidos, não foi nada desprezível" (MUZART, 2000, p.18) naquele século e que as escritoras estavam cientes de sua subalternidade e expressavam isso em suas obras, travando lutas importantes para tentar mudar o cenário da literatura nacional (DUARTE, 2016). No caso das escritoras do século XIX, o que parece ter acontecido é que "estranhamente, tudo foi sendo paulatinamente esquecido a partir do século XX - melhor dizer do Modernismo" (MUZART, 2000, p.18). O apagamento de Dinah Silveira de Queiroz pode ter relação com o de suas companheiras do século anterior, uma 
vez que Duarte (2016, p.9-10) chama atenção para o fato de que a baixa quantidade de mulheres escritoras convidadas para o evento é um dado de silenciamento das autoras que começaram a produzir entre as décadas de 1920 e 1930.

É interessante verificar que a luta das mulheres por direitos sociais se mistura à sua inserção no campo literário, não são movimentos desconectados. Alijadas das posições de poder, elas foram muitas vezes relegadas e ficaram às margens. O que se percebe é que as questões complexas de gênero dão a tonalidade da permanência do apagamento, mas não apenas, muitos desses silêncios são interseccionados por outras demandas como raça, classe, sexualidade. O tipo de literatura que elas produzem também contribuem para esse processo de exclusão dinâmico.

No âmbito da Ficção Científica Brasileira, ao estabelecer a Primeira Onda, convidando nomes como Dinah e Jerônymo, escritores com trânsito em jornal, cinema e rádio, o editor Gumercindo Rocha Dorea procurou aproximar-se do modelo de mercado estadunidense para ficção científica no início do século XX: uma literatura inserida em indústria de massas, com produção e consumo em escala industrial, em que a rádio, o cinema e depois a televisão desempenham papel tanto para difundir quando para adaptar obras. Entretanto, se nos EUA a FC será leitura destinada às classes populares distribuídas em pontos de venda em estações de trem e ônibus e bancas, compradas entre o trajeto da casa ao trabalho a centavos de dólar - as pulp fictions ${ }^{2}$-, no Brasil, não será possível estabelecer este modelo.

2 Embora o termo pulp faça referência a um tipo de papel mais barato, em oposição ao papel encerado, o termo pulp magazine designa o formato da publicação: $7 \times 10$ polegadas com 128 páginas. 
Na tese sobre o pioneirismo de Jeronymo Monteiro na indústria cultural brasileira, Marina Oliveira ressalta as óbvias barreiras sociais da década de 1930, "fazendo com que a produção e o comércio de livros fossem praticamente inexistentes em termos de mercado" (2018, p.131) - Braulio Tavares (2011, p.62) irá localizar a produção de Jeronymo como ponto de inflexão entre a influência das pulp fictions norte-americanas e da tradição romances científicos europeus, a exemplo de Flammarion, Verne e Wells.

Antonio Candido, em Literatura e Sociedade, traz dados sobre o analfabetismo no Brasil no início do século: 75\% em 1920 e 57\% em 1940 (2006, p.144). O país, que emerge do pesadelo de séculos de sistema escravocrata com desigualdade acachapante, não conseguirá criar público suficiente para uma indústria dessas nas classes operárias na década de 1960. Até hoje, a leitura é um privilégio traduzido em capital social, aspecto que a torna exclusiva de uma elite intelectual e cuja popularização é vista como suspeita, pois sua difusão é ameaça disruptiva ao estratificado sistema social brasileiro. Assim, mesmo contando com nomes bastante conhecidos do público leitor, como Dinah e Jeronymo, o alcance das obras da GRD será limitado a essa elite intelectual urbana.

Ainda na discussão a respeito do subdesenvolvimento da cultura das pulp fictions no Brasil, Alexandre Meireles da Silva expõe dois argumentos: o de Bráulio Tavares a respeito do papel da tecnologia "no processo de formação da sociedade estadunidense" (TAVARES Apud SILVA, 2008, p.264), que não encontrará similar brasileiro; e o de Murilo Garcia Gabelli, ressaltando "a influência europeia, em particular inglesa e francesa, sobre o desenvolvimento da literatura especulativa" (GABELLI Apud SILVA, 2008, p.264) na passagem do século XIX e XX. 
Nessa esteira, Fabiana Pereira (2005) argumenta que a cultura literária brasileira privilegia expressões miméticas ("realistas", nas palavras da pesquisadora), bipartindo-se o cânone na (a) vertente erudita - inicialmente francófila e europeia, tolerando expressões estadunidenses - e na (b) vertente popular, cujas obras encarnam mitos da nacionalidade, "tornando-se um capital simbólico através do qual o intelectual periférico se diferencia, positivamente, de seus pares de Primeiro Mundo" (PEREIRA, 2005, p.119). Dessa maneira, elegem-se elementos apaziguadores da cultura popular nacional amalgamados a uma tradição importada. A montagem não suportará o enxerto da ficção científica, pois, além de fugir da francofilia dominante, se trata de uma literatura popular desde sua origem, destinada ao operariado do hemisfério norte. Conforme resume Pereira com precisão: "não é suficientemente erudita, nem enraizada no solo popular mestiço, dois aspectos institucionalmente valorizados como características genuínas da cultura nacional" (2005, p.114-115).

Também corrobora o fato da produção da Primeira Onda da FC, diante do golpe de 1964, não formular utopias ou mesmo obras radicalmente antagônicas ao posicionamento colonialista brasileiro na ordem mundial da Guerra Fria, preferindo sugerir críticas oblíquas, não conseguindo angariar a simpatia da esquerda militante e organizada, público que poderia, eventualmente, se interessar por um conteúdo proletário, inclusive, é notório que a Geração GRD, em âmbito pessoal, não apresentava uniformidade ideológica - ao contrário, era composta desde Gumercindo Rocha Dorea à direita, "participara ativamente do movimento integralista de Plínio Salgado, e num primeiro momento apoiava o novo 
Governo" (PEREIRA, 2005, p.36), até André Carneiro, "anarquista, fichado no DOPS e passou parte dos anos de chumbo fugindo dos militares" (2005, p.36).

Passado o período candente dos anos de chumbo, a crítica posterior, mesmo à esquerda, que poderia se interessar pelo conteúdo por sua dicção popular e crítica aos usos da tecnologia no controle social, também não se volta às literaturas insólitas. 0 comportamento não é exclusivo do Brasil, pois dificilmente a FC dos EUA teria a expressão crítica atual sem a colaboração de acadêmicos como Fredric Jameson - respeitado por ser sua crítica ao pósmodernismo, embora também trabalhe com FC. China Miéville identifica o fenômeno como "um elitismo cultural de esquerda entre marxistas" (MIÉVILLE, 2014, p.108), afinal, "livros 'realistas' podem até fingir tratar do 'mundo real', mas isso não significa que nele reverberam com maior integridade e discernimento" (2014, p.108). O escritor britânico argumenta que "um romance presumidamente 'realista' sobre as desavenças de famílias de classe média, que pareçam hermeticamente fechadas, postas de fora dos conflitos sociais mais amplos, seria menos escapista do que, digamos, Ratos e gárgulas, de Mary Gentle" (2014, p.110).

Ursula Le Guin, na conhecida palestra Why americans are afraid of dragons? ("Por que os americanos têm medo de dragões?", publicada em 1979), insere uma provocação ainda mais abrangente: leitores dos EUA olham com suspeita ou desprezo obras de cunho imaginativo, pois não conseguem se afastar da ética do trabalho, sempre destinada a se concentrar em resultados e em produtividade, impedindo que se admita a leitura por prazer. Afasta-se essa literatura insólita como uma distração, pois não 
apresenta justificativa imediata "educacional". O entretenimento só poderia significar comportamentos autoindulgentes ou escapistas (acrescenta-se que, nos discursos à esquerda, a postura é chancelada pela crítica rasa contrária a "cultura de massa", como se existisse algo à venda nas livrarias que seja produzido em uma esfera separada do sistema capitalista). Ao final do texto, Le Guin (1979) sugere, inclusive, que a postura anti-ficção seja relacionada à construção da masculinidade, bastante complexa, mas que poderia ser resumida na necessidade do afastamento de conteúdos "femininos" ou "infantis".

Com esse encadeamento, pode-se entender a lógica que rege o apagamento da obra de Dinah Silveira de Queiroz. Sua tentativa em produzir uma literatura de dicção popular é lida como uma escrita indulgente, não trazendo aquele fabuloso "desafio ao intelecto". Ainda traz um comportamento disruptivo, pois "não sabe se comportar" como digna representante da elite cultural - com uma postura democrática, se propõe a discutir, de igual para igual, sem usar pseudônimo, suas reflexões com leitoras sobre assuntos que vão de flanelas à política internacional. Pior, a escritora alerta que é importante se prestar atenção a questões tecnológicas diante de um país que assiste, de forma bastante passiva, o pacto colonial sendo mais uma vez renegociado, no qual se exige que a produção de ponta tecnológica nunca fique ao sul do Equador.

Não é à toa que, ao publicar seu primeiro livro de ficção científica, Eles Herdarão a Terra, Dinah desculpa-se pela incursão: "Perdoem-me, queridos, se os levo a participar destas líricas vadiagens, dessas absolutamente informais escapadas ao Território do Absurdo" (QUEIROZ Apud CAUSO, 2013, p.177). Mesmo que, 
sem pedir desculpas, volte a "cometer" um novo livro de FC depois, a autora certamente imagina a audácia do empreendimento.

\section{COMBA MALINA: 50 ANOS DEPOIS}

Na década de 1970, no Brasil, as lutas feministas se configuravam de maneira diferente de outros países. Além das demandas próprias do movimento, as mulheres brasileiras estavam preocupadas com a conjuntura histórica, que lhes impôs que "se posicionassem também contra a ditadura militar e a censura, pela redemocratização do país, pela anistia e por melhores condições de vida" (DUARTE, 2003, p.165). Dinah Silveira de Queiroz, como vimos ao longo desse estudo, não se eximia do debate e procurou ao longo de sua carreira literária enfrentar as mais diversas questões sociais do seu tempo.

Em Comba Malina não foi diferente. Publicado em 1969, pouco depois da promulgação do Al-5, o livro promove diálogo com esses dois contextos sociais: antecipa e procura dar conta de alguns aspectos da luta das mulheres, tensionando o machismo e o lugar destinado a elas na sociedade; e problematiza o endurecimento da repressão e do regime ao questionar os estados autoritários, o controle da mídia, a herança escravocrata e as relações coloniais. Deflagra ainda a intolerância contra povos originários e alerta para o medo irracional do "outro" como um sujeito coletivo pautado na diferença.

As reivindicações feministas da época também estavam preocupadas com o debate a respeito da sexualidade, o prazer feminino e o acesso ao aborto. A noção de que o corpo das mulheres não pertencia ao estado, mas tão somente a elas, apareceu como uma questão bastante importante que 
recuperava, após mais de sessenta anos, as inflamadas discussões que socialistas e anarquistas do início do século $X X$ haviam promovido sobre a sexualidade. O planejamento familiar e o controle da natalidade passam a ser pensados como integrantes das políticas públicas. (DUARTE, 2003, p.165)

A preocupação com a representação feminina, com o direito da mulher ao próprio corpo e com as lutas feministas está presente em Comba Malina como um todo: na denúncia da perseguição da cultura cigana e da caça às bruxas, configuradas nas mulheres de culturas dissidentes, como acontece no conto homônimo ao livro; pela presença de mulheres na conciliação de conflitos entre as espécies planetárias, como acontece em "Os Possessos de Núbia" e "Eles Herdarão a Terra"; na reivindicação de subjetividades femininas dissidentes, como acontece em "Ânima" e "O carioca".

Em "Os Possessos de Núbia" a questão do direito ao corpo é o mote inicial da história. Num futuro distante, conhecemos Bruno, o protagonista que não aceita que a esposa Bella conceba seus filhos de modo natural, como há muito tempo não se fazia no planeta Terra. Em uma época em que a geração de bebês é mediada por um controle de natalidade que previa que a mãe moderna tivesse filhos em cubas de porcelana, em vez do próprio ventre, a escolha de Bella era considerada brutalizada e digna de vergonha porque subverte as "virtudes femininas de submissão e silêncio, nos comportamentos e gestos cotidianos" (PERROT, 2003, p.22), exigidas como centrais para as mulheres que eram esposas assemelhando o futuro da Terra com o contexto da condição feminina à época em que Comba Malina fora escrito. 
O retorno da geração da vida para o corpo da mulher, na história, é visto como o retorno do feminino para um lugar de animalização, que remonta práticas ancestrais inferiores: "foi assunto de controvérsias infindáveis nos jornais de imagem concreta, essa criança que abalou as boas maneiras das mulheres de então. Falouse muito daquela fêmea que desprezava os conceitos altamente civilizados da mãe moderna" (QUEIROZ, 2001, p.21). A mulher de Bruno não havia apenas quebrado normas, mas também havia atravessado uma fronteira irreversível que a tornava não apenas abjeta, mas alguém capaz de contaminar a sociedade com práticas transgressoras. Ela podia influenciar negativamente outras futuras mães. Seu corpo, agora reivindicado, era uma afronta para as conquistas estabelecidas, uma mácula para a vida social.

Segundo Elizabeth Grosz, a oposição entre macho e fêmea, estabelece-se sob o signo da diferença. A presença de um binarismo determina a correlação do homem como mente e da mulher como corpo e este estatuto "não é contingente ou acidental, é central ao modo pelo qual a filosofia se desenvolveu historicamente e ao modo como ela se vê ainda hoje" (GROSZ, 2000, p.49). No trecho supracitado de "Os Possessos de Núbia", é a esse binarismo que a autora procura criticar. As práticas sociais da então era moderna da Terra do futuro se configuram como tentativas de disciplinamento das paixões e corpos femininos, considerados dissidentes.

E à essa afronta imposta por Bella, a emancipação feminina, a virilidade de Bruno não pôde suportar. Abandonando a mulher e os dois filhos, ele se muda para a pequena colônia terráquea localizada em Núbia. O planeta é apresentado ao leitor como uma terra de promessas e pretensa felicidade, que esconde, por meio 
do controle do acesso às informações e da manipulação da droga chamada fixêmio, que propicia o prazer e a tranquilidade, complexas camadas de relações de poder.

Capitão Welsch é o homem que comanda a colônia com mãos de ferro, em uma clara alusão aos regimes autoritários e suas consequências nefastas. De forma distópica, a máquina orwelliana de manipular notícias é instaurada no planeta-colônia pelos militares para que ninguém queira regressar à Terra. Além da governança, o cotidiano é extremamente paramentado e militarizado, com a presença de um exército de robôs a fim de garantir a segurança. Aqui, segundo Fernando Cristóvão (1989), o progresso e a tirania andam de mãos dadas. Welsch esconde as reais condições de vida no planeta Núbia ao mesmo tempo em que distorce dados, incentiva a alienação da população, e transforma a representação da vida na Terra em uma realidade impossível para aqueles que vivem longe. Entretanto, na medida em que a narrativa avança, percebemos que o equilíbrio da vida na colônia é matéria frágil e difusa.

Para garantir que nubienses se mantenham atados às suas práticas de controle, o capitão conta com a ajuda de uma figura feminina curiosa: Drusa, a psicóloga do grupo. Com técnicas nada convencionais, ela contorna as expectativas e ansiedades da colônia, e soluciona os conflitos individuais e coletivos, levando seus pacientes a retornarem para um lugar de infância doloroso e birrento. As demandas desses adultos que se transformam em crianças instáveis só podem ser apaziguadas e reconciliadas por meio da aplicação de carícias e beijos na boca dados pela própria psicóloga, "numa cordialidade quente, que, generosa, oferecia a todos os de sua clínica" (QUEIROZ, 2001, p.22). Com a metodologia, 
Drusa estabelece uma relação em que a comunidade se torna dependente emocionalmente de sua figura.

A autoridade da personagem há de ser criticada. Se por um lado é transgressor e disruptivo o jeito como a narrativa a apresenta ao leitor, evidenciando uma mulher que se coloca socialmente e estabelece um poder enorme sobre os que estão à sua volta, por outro a maneira como ela exerce esse poder ainda vem de um espaço de representação feminina nebuloso e estereotipado. Apesar de ser um elemento de estranhamento, que atesta a frágil saúde mental daquela comunidade, não deixa de fazer eco ao clichê da sensualidade excessiva das mulheres no espaço, tão presentes nas capas de pulps dos EUA. Por mais que as atitudes de Drusa estejam vinculadas à área da ciência e ela tenha total compreensão de suas aptidões de cura e cuidado, a perspectiva pela qual ela empenha suas ações é de um corpo que está colocado à disposição da sociedade e em sacrifício pelo "bem maior". Ainda é uma corporeidade que se empenha em controlar as paixões.

Núbia é iluminada por Glauco, seu perigoso sol, que ao longo da trama protagoniza a tentativa de extinção da vida no planeta e desempenha o importante papel de deflagrar as contradições em que vivem os colonos. $O$ ápice da trama se dá quando as temperaturas se elevam de tal maneira que "a segurança e a felicidade artificiais volatilizam-se" (CRISTÓVÃO, 1989, p.125), derretendo junto com os robôs, e com "a diminuição da dose de fixêmio volta a incerteza e a angústia" (1989, p.125 - grifo do autor). Não se sabe ao certo se o calor brutal, ao qual Núbia é exposta, contraria os cálculos e expectativas dos especialistas comandados pelo Capitão Welsch ou se haviam dados secretos protegidos por esquemas de controle 
da informação do próprio capitão. O certo é que a espreita da morte iminente faz com que a pequena comunidade se encastele e fortaleça em suas próprias mediações, para suportar o calor intenso e as ações de Glauco.

Como um oásis em meio ao caos do solo nubiense, a colônia descobre, por meio do episódio, a existência de povos originários que viviam no centro do planeta. Dentro do discurso oficial militar,

Os colonos enviados ao planeta não foram
informados da existência desses habitantes
subterrâneos, já que se pensava que o
conhecimento de sua existência iria desviá-los de
sua sociedade utópica, livre da guerra, da doença
e dos desastres naturais que atingem a Terra.
(GINWAY, 2005, p.58-59)

Numerosos, desesperados e fugindo da morte, esses povos originários buscam auxílio na pequena comunidade que, protegida por uma redoma de vidro e consumida pelo pavor, Ihes nega ajuda. Um a um, os seres daquele povo até então desconhecido, vão morrendo às portas da colônia.

Comandados por Capitão Welsch, os terráqueos habitantes de Núbia agora se parecem mais com tiranos do que com seres que se pretendiam evoluídos. Podemos verificar nesse trecho de tensão uma metáfora contundente que nos remonta aos períodos de um Brasil colonial ou mesmo se assemelha às violências da ditadura militar. Segundo Sueli Carneiro (2019), a herança colonial e escravocrata do país é a origem das construções de nossa identidade nacional balizada na diferença e da subalternização dos negros pelos brancos. No conto de Dinah Silveira de Queiroz, essa diferença se estabelece entre os terráqueos e o povo recém-conhecido do centro do planeta. 
Ao problematizar a maneira como os colonizadores encaram os que buscam ajuda, a autora estabelece limites bem definidos para o "nós" e o "eles", que se clivam não apenas no não entendimento desse "outro" coletivo, mas também no desejo de aniquilação. A crítica que emerge do texto muito se assemelha às disputas discursivas e sociais travadas no contexto da história do país e pode se configurar como uma denúncia à brutalização e animalização com que negros e indígenas têm sido representados. A elite, representada pela pequena colônia, dizima os povos que não reconhece como iguais.

Bruno, num ato desesperado, lança-se para fora da redoma a fim de salvar um bebê à beira da morte, nos braços da mãe, fechando um ciclo iniciado no momento em que abandonou Bella e seus filhos. Seu ato de reparação é tardio e ele sucumbe à morte. É nesse contexto que aparece mais uma figura feminina: Célia, que ocupa o papel de mulher solteira desimpedida e também de prostituta. É ela quem conclui o ato de Bruno e resgata o bebê salvando-Ihe a vida. Em contraposição com a destruição promovida por Glauco, Célia é apresentada como a conciliadora dos dois mundos: a colônia de invasores, que tomam posse de Núbia e da possibilidade de sobrevivência no planeta, e, ao garantir a sobrevivência do bebê e assumir sua criação, permite a continuidade do povo originário à beira da destruição.

Segundo Michelle Perrot, em sociedades patriarcais, o modelo que se espera ser seguido por mulheres prevê o recato, a contenção dos gestos e das falas, a não ocupação do espaço público, uma vez que "todas as particularidades dos corpos singulares devem ser amenizadas até o desaparecimento e à conformidade a um 
modelo impessoal" (PERROT, 2003, p.15). Bella, Drusa e Célia não se contentam em cumprir o papel que lhes é imposto socialmente pela tradição canônica, pautado subserviência, e elas rompem com os códigos de conduta limitadores e assumem o protagonismo das situações. Ao mesmo tempo, a transgressão de Bella e Célia possui um destino bastante esperado pela família tradicional: a maternidade, mostrando o limite que a ruptura teria no espectro da narrativa - esse fechamento resignado aponta para o tempo histórico de produção do texto, 1969, época do ocaso das utopias do país do futuro.

A ruptura social também é tematizada em "Ânima". O conto nos traz a experiência ousada do professor Jorge Alves em fazer uma expedição ao planeta Vênus chamada "Operação Ânima". Nela, sondas espaciais e uma equipe de condenados à morte, liderada por ele, irão coletar dados para viabilizar o projeto de propulsão dos espíritos e do entendimento de ânima, uma espécie de potência e energia da alma. A viagem espacial funciona aqui também como uma espécie de resgate e alternativa àqueles que foram alijados da sociedade.

A proposta, apresentada em assembleia das Nações Unidas é vista como chacota mundial e figura como uma grande piada fadada ao fracasso. A viagem espacial só ganha certa projeção quando Marta, uma garota brasileira à beira da morte, resolve pleitear uma vaga na expedição. Inicialmente, o cientista é contra, haja vista a incerteza das competências da menina, que era "demasiado imatura para transmitir experiência ou sensações quando voltasse à terra"; e os perigos da viagem, uma vez que não era "possível prever se, estando doente, o choque de ânima seria suportado por 
um corpo que, dentro em breve, estaria paralisado pela morte" (QUEIROZ, 2001, p.69). A indisposição foi apenas superada com a mobilização mundial em torno da inscrição da jovem, que tornou sua concordância inevitável.

O conto chama atenção não exatamente por sua narrativa elaborada, ou pelas experiências interplanetárias, que podem ser vistas em outras narrativas de Comba Malina, posto que na verdade, não propõe nenhuma grande reviravolta. Sua engenhosidade repousa na ousadia das atitudes de Marta. Se pensarmos que ter voz é ter condição de se colocar no mundo, podemos dizer que às mulheres, em geral, esse direito ficou prejudicado ao longo da história. Recusar a voz se configura como uma violência, posto que é a recusa do "direito de autodeterminação, de participação, de concordância ou divergência, de viver, de participar, de interpretar, de narrar" (SOLNIT, 2017, p.30). Ao pleitear a vaga, Marta luta por seu direito de autodeterminação, por sua necessidade de participar da vida pública.

Quando Dinah Silveira de Queiroz coloca Marta dentro da expedição para Vênus, a narrativa rompe com essa lógica de opressão, rompe com o silenciamento e a interdição e evidencia a menina como corajosa, capaz de se relacionar ativamente com o cientista e os demais companheiros de maneira igual. Ela toma para si o protagonismo pelos seus atos e pelo que lhe resta de vida.

Ao renunciar ao claustro da casa e da doença, borra as fronteiras e os limites do lugar onde ela, como mulher, pode estar e ressignifica seu corpo e sua subjetividade. Isto porque, segundo Helena González Fernández (2009), o desejo oriundo de um corpo 
desconforme, fragmentário, não aceito socialmente, põe em crise os modelos hegemônicos e harmônicos, que imprimem padrões. Um corpo enfermo é, de certa forma, um espelho que revela ao "eu" tudo aquilo que ele reconhece como abjeto, que lança esse "eu" ao desconforto do desconhecido do "outro". Ciente de suas limitações, Marta estabelece confronto direto com Jorge Alves, ao não se sujeitar, ao transformar a sua doença em produção de conhecimento.

Já em Vênus, as neblinas e brumas denunciam uma realidade fugidia em que o tempo não é contado do mesmo jeito que na Terra, um lugar em suspensão. A dialética estabelecida entre o cientista cético a respeito de assuntos que escapem à ciência e a menina em busca da centelha de vida fica ainda mais evidente ao final do conto. Marta decide ficar em Vênus e fazer com que sua ânima se desprenda do corpo, não regressando para casa:

Você sabe que eu vou morrer, e então a minha sobrevivência será uma dúvida. Eu não creio no céu, como outras pessoas. Aqui, Jorge, eu poderia perder a minha figura, mas estou certa de que jamais deixaria de sentir a presença das coisas vivas que estão nesse mundo. (QUEIROZ, 2001, p.76)

Como já vimos, "ser privado de voz é ser desumanizado ou excluído da sua humanidade" (SOLNIT, 2017, p.28) e ao decidir de que maneira quer morrer, Marta recupera definitivamente seu lugar no mundo, sua humanidade ao não permitir que outras pessoas Ihe digam como findar sua própria existência. Ela opera mais uma ruptura na tradição, abre mais uma fenda nas normas patriarcais.

Se por um lado Jorge Alves acreditava estar ensinando e controlando as variáveis de sua pesquisa para o desenvolvimento 
da ciência, é a menina enferma que lhe ensina algumas lições a respeito da vida, de como permanecer no mundo para além da matéria. Ao tentar dissuadi-la, o cientista também sucumbe e não regressa. Mais uma vez, a narrativa aponta para o momento histórico, para o fechamento de possibilidades: a transgressão da garota, que se transforma em mulher ao longo da viagem, como se a própria autonomia lhe concedesse experiência de vida, também esbarra no limite imaginário: falece. A mulher livre, desimpedida, resta somente como ideal, somente a sombra de um sonho.

Dinah Silveira de Queiroz opera o deslocamento do centro da ação e da narrativa: da necessidade de uma viagem interplanetária como um grande feito, cujos benefícios de suas descobertas são avanços para a ciência, para a importância de colocar uma lupa num ponto do cosmos e compreender as conexões humanas. Vênus é o palco em que as tensões do cotidiano terreno se estabelecem e se resolvem. Vida e morte, as intensas disputas travadas pelas mulheres e a corporeidade das experiências aparecem em diálogo, revelando a ficção científica como ferramenta de crítica para as às relações verificadas na sociedade.

Em entrevista à David Dunbar, vindo da Universidade do Arizona em 1972 (primeiro pesquisador a se deter sobre a produção brasileira em FC), Dinah comenta a respeito de suas referências: Júlio Verne e H. G. Wells. É interessante, entretanto, verificar que em Estrelas o Meu Destino de Alfred Bester (1956) haja um mecanismo muito semelhante de teletransporte proposto por Dinah em "Ânima": Bester propõe o jaunte, um deslocamento causado por medo profundo, pânico, ódio ou dor. Embora parecido, o mecanismo à brasileira é oposto, movido à meditação e tranquilidade. 
Se iniciamos nosso processo de análise dos contos verificando como os terráqueos também poderiam ser invasores e algozes em "Os Possessos de Núbia", encerraremos esse percurso pela narrativa escrita de Comba Malina, observando como o contrário se deu. Inicialmente publicado em 1957, na revista Jóia, "Eles Herdarão a Terra" é o primeiro texto de ficção científica de Dinah Silveira de Queiroz. Trata-se de uma invasão marciana, na qual a possibilidade de fuga não é possível.

Marcos, o narrador da história, conta os acontecimentos desde que conhecera tardiamente sua irmã Tuda, passando pela morte misteriosa do pai, até a chegada de um forasteiro mal-intencionado. O Farol da Ilha da Mola, no Rio de Janeiro, é o cenário para um projeto de dominação mundial que está além da vontade da família do protagonista.

No início do conto percebemos o ambiente familiar hostil e machista enfrentado por Tuda. Pai e irmão constantemente diminuem a garota ou a tratam sob a máxima de "mulher é bicho doido" (QUEIROZ, 2001, p.103), deixando claro o desconforto que sentem com a presença feminina na casa: "é o que se ganha, minha filha. Você também, como as outras, não merece confiança" (2001, p.103). Tuda chora, mas não chega a enfrentar os dois, ela é uma estrangeira entre os seus e no espaço privado Ihe é requisitado o silêncio.

O desconforto de Marcos com a irmã é tão grande que quando o marciano chega, e ela avista algo que acredita ser um paraquedas no céu e corre para contar-lhe, ele não acredita: "você acha que um pára-quedas podia ficar sempre imóvel, aberto sozinho?... Ele 
não está em cima das árvores, está entre as árvores. Venha tomar seu café, e depois vamos ver essa novidade que você descobriu" (QUEIROZ, 2001, p.107). A maneira como trata Tuda não demonstra carinho ou cuidado, é antes de tudo condescendente e vê a situação com certa ironia, acreditando tratar-se de algum delírio da irmã.

O encontro com o marciano, que chegara à casa naquela manhã, é inicialmente confuso. A figura exótica desperta mistério e curiosidade nos irmãos. Tuda é atenciosa e quer saber mais sobre o forasteiro, enquanto Marcos, desconfiado, sente o perigo se aproximar. A comunicação se modifica ao longo da narrativa: de início, o marciano procura estabelecer contato balbuciando palavras em português e, posteriormente, se comunica por meio de telepatia com os dois. A telepatia se dá através de um raio de luz que conecta a mente dos interlocutores.

O plano de invasão é revelado a Marcos, assim como uma possível conexão inicial entre seu pai e o povo de Marte. A colonização da Terra pelo povo do outro planeta é justificada sob as seguintes perspectivas, conforme se verifica no conto de Queiroz (2001, p.113): os terráqueos não merecem o mundo que tem; o povo marciano é mais evoluído; as condições precárias fazem com que eles vivam de maneira artificial; as instalações da Terra os lembra o quanto eles são infelizes, fato que lhes abre o canal para a apropriação. Entretanto, é claro que esse processo se dará de maneira autoritária e violenta, mediante guerra, uma vez que os forasteiros acreditam serem os verdadeiros herdeiros da Terra.

Para a colonização desse novo mundo pelos marcianos havia ainda o elemento de subjugação das mulheres terráqueas. O futuro 
colonizador diz a Marcos que deseja Tuda. Na narrativa, apropriarse de Tuda remete à violação histórica de mulheres como um ato de guerra. No "contexto de conquista e dominação, a apropriação social das mulheres do grupo derrotado é um dos momentos emblemáticos de afirmação de superioridade do vencedor" (CARNEIRO, 2019, p.314). Ao evocar tais práticas violentas, Dinah Silveira de Queiroz mais uma vez faz dura crítica às práticas coloniais e ao lugar imposto à mulher na história da humanidade.

No conto, fica claro que a colonização se dará pela Terra, pelo corpo e pela mente com as seguintes passagens: "vocês pensam que têm as suas mulheres, mas não possuem suas mentes" e "vocês nada sabem do requinte que é a posse de um espírito" (QUEIROZ, 2001, p.113). Conforme a passagem, verifica-se que o anseio de dominação não se basta em possuir matéria, é preciso se apossar da alma, da pessoa como um todo, para que não haja perspectiva de salvação da opressão. Tuda é tratada pelos dois como um objeto, um corpo disponível ao prazer masculino, que deve se submeter às vontades dos homens.

A discussão sobre o destino de Tuda se dá numa conversa entre homens da qual ela não participa. Ao dizer que a moça irá com ele por sua própria vontade, o marciano ignora que vontade tem a ver com autodeterminação e não é possível desejar plenamente quando se está excluído do processo de decisão. $\mathrm{Na}$ ocasião, a garota já havia sido posta para dormir pelo intruso, não tem como se autodeterminar. O invasor trata de seu corpo e subjetividade como uma negociação entre os dois mundos. À luz da história de violências de nosso país, podemos verificar que a reificação de Tuda se assemelha à subalternização de mulheres 
negras e indígenas, alvos da exploração predatória do período colonial aos nossos dias.

Ainda que o personagem marciano informe: "levarei sua irmã daqui com sua própria vontade" (QUEIROZ, 2001, p.113), percebese, pela narrativa, que o sono de Tuda, imposto pelo alienígena, era também um jeito de manipulação do desejo. A moça não é "uma mediadora e salvadora", como acredita Cristóvão (1989, p.127), seus atos e a maneira de conversar com a figura masculina do colonizador não determinam seu destino: Tuda é uma vítima.

A violência sexual que sofre vincula o estupro como "uma visão do corpo masculino como arma e do corpo feminino (no estupro heterossexual) como inimigo" (SOLNIT, 2017, p.43). Dinah Silveira de Queiroz alia fiç̧ão e realidade para evidenciar, por meio da narrativa, esse suposto direito histórico de violar mulheres tão amplamente denunciado por estudiosas como Sueli Carneiro (2019). Em "Eles Herdarão a Terra", a colonização do planeta se assemelha à colonização do feminino.

Dinah Silveira de Queiroz opera crítica veemente aos estados de guerra, à alienação da sociedade: "vocês estão apodrecendo há séculos. Os seus líderes determinam, e vocês se matam aos montes, mas ainda não descobriram a origem dessas brigas, do suicídio de sua humanidade" (QUEIROZ, 2001, p.113). São a brutalização e a desumanização que permitem as mais diversas atrocidades.

Em outra ocasião, Dinah Silveira de Queiroz sugere que sua ficção científica esteja próxima às fábulas, em entrevista para David Dunbar em 1972: "No século XVIII se brincava, se diziam grandes verdades por intermédio dos animais. Hoje nós dizemos 
essas verdades usando marcianos e outros seres que nós mesmos sabemos que não podem existir" (DUNBAR, 1976, p.1). A autora alerta, por meio da ficção científica, para um futuro inevitável e aterrador em que o homem é o seu próprio algoz. A presença de um alienígena, cujo desejo é colonizar a terra de forma violenta e autoritária, e a iminência da invasão marciana que figura em "Eles Herdarão a Terra" é o canal por meio do qual a deterioração será deflagrada.

Para finalizar o tópico e para trazer um pouco do discurso da própria autora a respeito de sua produção de ficção científica, Dinah diz que não haveria uma definição única para a FC que produz, e sim três:

Poderia ter várias definições porque eu faço vários tipos de ficção científica. Uma é a que já falei, a ficção científica unicamente como fábula; outra é a ficção científica ou conto ou romance organizado numa fábula, mas dentro de uma base científica. Outra eu acredito que fica entre o mundo do sonho e o mundo da realidade científica. Eu posso dizer só três. (DUNBAR, 1976, p.4)

Essa amplitude na definição apontaria para um traço experimentalista na forma de narrar da nascente FC, bastante flexível em termos de tratamento literário, podendo ser trabalhada no formato da fábula moral - tônica do livro em análise, como ocorre na narrativa examinada, "Os Possessos de Núbia", até lançar mão de recursos da prosa poética para criar sensações oníricas de "Ânima".

\section{DINAH SILVEIRA DE QUEIROZ HOJE}

Dos estudos que procuram dar conta das autoras do século XIX, aos estudos que mapeiam as ausências na literatura 
contemporânea, diversas pesquisas têm se debruçado sobre a presença das mulheres na literatura brasileira. Tal visibilização é uma forma de responder às demandas e lutas que elas têm travado na sociedade e no campo literário por reconhecimento e direitos. Nas primeiras décadas do século XXI, esse trabalho parece imperioso e cada vez mais aceito em programas de pesquisa. Projetos para fortalecer a leitura, fora do âmbito acadêmico, também aumentaram significativamente a rede entre mulheres - a exemplo do projeto nacional Leia Mulheres, com clubes de leitura ao redor do país. Entretanto, o otimismo deve existir, mas, de forma crítica, pois um apagamento puxa outros apagamentos - resgatar, analisar e refletir criticamente a respeito de obras à penumbra somente desvela outras injustiças históricas, por exemplo, as ausências de mulheres negras na Ficção Científica Brasileira.

Com relação ao insólito ficcional, também se assiste a esforços significativos de pesquisas, buscando não apenas reconhecer, mas catalogar, organizar e abrir espaços para possibilitar análises futuras. Exemplo é a obra de Matangrano e Tavares (2018), que se propõe não só a resgatar nomes que escreveram FC do século XIX ao XXI, mas nomeia um capítulo da obra: "Porque mulheres também escrevem ficção científica" (2018, p.103-110), trazendo ao mesmo tempo ênfase e incômodo sobre os olhares a respeito dessa produção. O aumento do interesse de estudos dessas literaturas é visto pelo incremento de trabalhos acadêmicos, como o Grupo de Trabalho Vertentes do Insólito Ficcional (Associação Nacional de pós-Graduação e Pesquisa em Letras e Linguística). No âmbito editorial, há um florescimento de iniciativas de projetos editoriais em casas de diferentes portes para títulos brasileiros de 
ficção científica como Aleph, Avec, Damme Blanche, Draco, Morro Branco, Monomito, Rocco, Plutão. Inclusive, anuncia-se que a editora Plutão republicará Eles Herdarão a Terra de Dinah Silveira de Queiroz ainda em 2019.

Pioneira na luta pela inclusão e permanência das mulheres em espaços literários de poder, Dinah Silveira de Queiroz é uma autora que urge ser lembrada não apenas por sua atuação no meio literário, mas também por sua intensa e extensa obra, por seu compromisso em transformar assuntos considerados reservados à elite cultural em matéria de diálogo popular, por ter sido popular e muito lida. Uma reparação que nos abre novas possibilidades para os tempos vindouros. Mesmo diante de um momento histórico desafiador para a pesquisa no país, trazer Dinah de volta nos traz uma abertura utópica, chances de se conhecer novas vozes, formas de atuação, de nos compreender mais uma vez o ontem para acertarmos no agora.

O que se faz agora, ao resgatar o passado, é direcionar a mesma pergunta de Dinah para mais 50 anos ao futuro, nessa máquina do tempo estranha de papel, memória e afeto. Que destino terá a obra de uma escritora daquela época quando estiver, ao zênite, o sol do século XXI?

\section{REFERÊNCIAS}

ALMEIDA, Veronica Eloi de (2012). "A Muralha e a representação indígena na televisão, na literatura e nas ciências sociais". PROA Revista de Antropologia e Arte, 1(4), 1-16. In https://www.ifch.unicamp.br/ojs/index.php/proa/article/ view/2359 Acesso em 20.Out.2019.

ANDRADE JÚNIOR, Lourival (2013). "Os ciganos e os processos de exclusão". Revista Brasileira de História, 33(66), 95-112. In http://www.scielo.br/pdf/rbh/ v33n66/a06v33n66.pdf Acesso em 20.Out.2019. 
BITTENCOURT, Rita Lenira de Freitas (2018). "Dinah Silveira de Queiroz na Máquina do Tempo". In: BETTIOL, Maria Regina Barcelos; VELOSO, Maria Thereza. (Orgs.). Entre livros e discursos: a trajetória das mulheres da Academia Brasileira de Letras. Frederico Westphalen: URI. p.39-56.

CANDIDO, Antonio (2006). Literatura e sociedade. 9.ed. Rio de Janeiro: Ouro sobre azul.

CARNEIRO, Sueli (2019). "Enegrecer o feminismo: a situação da mulher negra na América Latina a partir de uma perspectiva de gênero". In: HOLLANDA, Heloisa Buarque de (Org.). Pensamento feminista: conceitos fundamentais. Rio de Janeiro: Bazar do tempo. p.313-321.

CAUSO, Roberto de Sousa (2013). Ondas nas Praias de um Mundo Sombrio: New Wave e Cyberpunk no Brasil. (Tese-Doutorado em Estudos Linguísticos e Literários em inglês). Faculdade de Filosofia, Letras e Ciências Humanas, Universidade de São Paulo, São Paulo. In https://teses.usp.br/teses/disponiveis/8/8147/ tde-12032014-123051/publico/2013_RobertoDeSousaCauso.pdf Acesso em 20.Out.2019.

COLLING, Ana Maria (2014). Tempos diferentes, discursos iguais: a construção do corpo feminino na história. Dourados: Ed. UFGD.

CRISTÓVÃO, Fernando (1989). "A ficção científica de Dinah Silveira de Queiroz". In: ALVES, Dário de Castro (Org.). Dinah, caríssima Dinah. Brasília, Belo Horizonte: edição do autor. p.121-132.

DUARTE, Constância Lima (2003). "Feminismo e literatura no Brasil". Estudos Avançados, 17(49), 151-172. In http://www.scielo.br/pdf/ea/v17n49/18402.pdf Acesso em 25.Jul.2017.

(2016). "A literatura de autoria feminina e os anos 30 no Brasil". Araticum, 14(2), 9-24. In https://www.periodicos.unimontes.br/index.php/ araticum/issue/view/106 Acesso em 27.Out.2019.

DUNBAR, David Lincoln (1976). Unique Motifs in Brazilian Science Fiction. (Tese - PHD em Filosofia). Departamento de Línguas Românicas, Universidade do Arizona. In http://hdl.handle.net/10150/289377 Acesso em 20.Out.2019.

FANINI, Michele Asmar (2009). Fardos e fardões: mulheres na Academia Brasileira de Letras (1897-2003). (Tese - Doutorado em Sociologia). Faculdade de 
Filosofia, Letras e Ciências Humanas, Universidade de São Paulo, São Paulo. In https://teses.usp.br/teses/disponiveis/8/8132/tde-19022010-173143/publico/ MICHELE_ASMAR_FANINI.pdf Acesso em 1.Out.2019.

FERNÁNDEZ, Helena González (2009). “Especulacións sobre o desexo: corpos venéreos, disconformes e fragmentados”. In: GONZÁLEZ, Olívia Rodriguez; PIÑEIRO, Laura Carballo (Orgs.). Novas achegas ao estudo da cultura galega: Enfoques literarios e sociohistóricos. A Coruña: Universidade da Coruña. p.159-175.

GINWAY, Mary Elizabeth (2005). Ficção científica brasileira: mitos culturais e nacionalidade no país do futuro. São Paulo: Devir.

GIROLDO, Ramiro (2012). Alteridade à margem: estudo de As Noites Marcianas, de Fausto Cunha. (Tese - Doutorado em Literatura Brasileira) - Faculdade de Filosofia, Letras e Ciências Humanas, Universidade de São Paulo, São Paulo. In https://teses.usp.br/teses/disponiveis/8/8149/tde-09012013-144133/pt-br.php Acesso em 1.Out.2019.

GROSZ, Elizabeth (2000). "Corpos Reconfigurados". Cadernos Pagu, 14(1), 45-86. In https://periodicos.sbu.unicamp.br/ojs/index.php/cadpagu/article/ view/8635340 Acesso em 31.Ago.2017.

LE GUIN, Ursula (1979). The Language of the Night: Essays on Fantasy and Science Fiction. Nova York: G. P. Putnam's Sons.

MATANGRANO, Bruno; TAVARES, Enéias (2018). Fantástico brasileiro - o insólito literário do romantismo ao fantasismo. Curitiba: Arte \& Letra.

MIÉVILLE, China (2014). "Marxismo e fantasia". Margem esquerda, 23(1), 107117. In http://bit.ly/34ws8k7 Acesso em 26.Out.2019.

MUZART, Zahidé Lupinacci (2000). "Pedantes e bas-bleus: histórias de uma pesquisa". In _-_-_- (Org). Escritoras brasileiras do século XIX - Antologia. Florianópolis: Editora Mulheres; Santa Cruz do Sul: EDUNISC. p.17-29.

(2013). "Lembrando Dinah Silveira de Queiroz". Navegações, Florianópolis, 6(2), 162-169. In http://bit.ly/2NyGKZi Acesso em 26.Out.2019.

OLIVEIRA, Marina João Bernardes de (2018). Jeronymo Monteiro: um precursor da indústria cultural no Brasil. (Tese - Doutorado em Letras). Faculdade de Ciências e Letras, Universidade Estadual Paulista, Assis. In https://repositorio. unesp.br/handle/11449/158296 Acesso em 1.Out.2019. 
PEREIRA, Fabiana da Camara Gonçalves (2005). Fantástica Margem: o cânone e a ficção científica brasileira. (Dissertação - Mestrado em Letras). Pontifícia Universidade Católica, Rio de Janeiro. In https://www.maxwell.vrac.puc-rio.br/ colecao.php?strSecao=resultado\&nrSeq=6493@1 Acesso em 3.Ago.2018.

PERROT, Michelle (2003). "Os silêncios do corpo da mulher". In: MATOS, Maria Izilda Santos de; SOIHET, Rachel (Orgs.). O corpo feminino em debate. São Paulo: Editora da Unesp. p.13-28.

QUEIROZ, Dinah Silveira de (2001). Comba Malina. Rio de Janeiro: Ediouro.

RÜSCHE, Ana (2019). "Comba Malina: a ficção científica de Dinah Silveira de Queiroz (e seu apagamento)". Suplemento Pernambuco. In http://bit.ly/34qfYZV Acesso em 26.Out.2019.

SILVA, Alexandre Meireles da (2008). "O admirável mundo novo da República Velha: o nascimento da ficção científica brasileira". Eutomia Revista de Literatura e Linguística, 1(2), 262-283. In https://periodicos.ufpe.br/revistas/EUTOMIA/ article/view/1941 Acesso em 31.Jan.2020.

SILVA, Cesar (2015). "Comba Malina, Dinah Silveira de Queiroz". Almanaque da Arte Fantástica Brasileira. In http://almanaqueafb.blogspot.com/search/label/ Dinah\%20Silveira\%20de\%20Queiroz Acesso em 20.Out.2019.

SOLNIT, Rebecca (2017). A mãe de todas as perguntas: reflexões sobre os novos feminismos. São Paulo: Companhia das letras.

STEFFEN, Ana Cristina (2019). Quando a mulher tem voz: a narradora-personagem de Margarida La Rocque: a ilha dos demônios, de Dinah Silveira de Queiroz. (Dissertação - Mestrado em Teoria da Literatura). Escola de Humanidades, Pontifícia Universidade Católica do Rio Grande do Sul, Porto Alegre. In http:// bit.ly/2PUVoNt Acesso 1.Out.2019.

TAVARES, Braulio (Org.) (2011). Páginas do futuro: contos brasileiros de ficção científica. Santo André: Casa da palavra.

THOMÉ, Cláudia (2015). Literatura de ouvido: crônicas do cotidiano pelas ondas do rádio. Curitiba: Appris. 